\title{
Enhancing health care for type 2 diabetes in Northern Brazil: A pilot study of pharmaceutical care in community pharmacy
}

\author{
Blície Jennifer Balisa-Rocha1, Viviane Gibara Guimarães ${ }^{1}$, Alessandra Rezende Mesquita ${ }^{1}$, \\ Patrícia Melo Aguiar ${ }^{2}$, Ines Krass ${ }^{3}$ and Divaldo Pereira de Lyra Jr. ${ }^{*}$ \\ ${ }^{1}$ Laboratory of Teaching and Research in Social Pharmacy (LEPFS), Federal University of Sergipe, Brazil. \\ ${ }^{2}$ Faculty of Pharmaceutical Sciences, University of São Paulo, Brazil. \\ ${ }^{3}$ Faculty of Pharmacy, The University of Sydney, S346, Pharmacy and Bank Building A15, NSW 2006, Australia.
}

Accepted 10 August, 2012

\begin{abstract}
To evaluate the impact of a medication therapy management (MTM) program on the clinical outcomes and the quality of life (QoL) of a group of elderly patients with type 2 diabetes mellitus (DM). The study was conducted in a community pharmacy in Aracaju, Brazil, from February to November 2009. A quasiexperimental, longitudinal, prospective study was conducted by intervention. The group patients received medication therapy management from a clinical pharmacist. A sample of convenience was obtained for patients of both genders aged from 60 to 75 years. Monthly visits were scheduled over 10 months. At these consultations, sociodemographic, clinical data were obtained. QoL assessment was conducted using a generic instrument-the Medical Outcomes Studies 36-item Short Form Survey (SF$36 \AA)$. In total, 34 completed the study. The mean age of the patients was 65.9 (4.7) years. In total, 117 DRPs were identified. Patients' baseline and final evaluation measures for glycosylated hemoglobin, capillary blood glucose, blood pressure, and waist circumference were significantly different $(p<0.05)$. The domains of QoL assessed by the SF-36® also shows significant differences between patients' baseline and final evaluation scores. The co-responsibility and active participation on the part of the elderly may have helped pharmacotherapy achieve its clinical and humanistic aims.
\end{abstract}

Key words: Medication therapy management, diabetes mellitus, elderly.

\section{INTRODUCTION}

Diabetes mellitus (DM) is a chronic health condition and relevant risk factor to cardiovascular diseases, especially in elderly (Wermeille et al., 2004). In practice, the treatments involve counseling on behaviour change by family physicians and primary care teams, and referral to exercise specialists and registered dieticians and drug therapy (Assunção et al., 2002; Chatterjee et al., 2012). Management of elderly patients with DM is more difficult because of certain inherent characteristics of this age group, such as the presence of comorbidities, pathophysiological changes associated with old age, and

\footnotetext{
${ }^{*}$ Corresponding author. E-mail: lepfs.ufs@gmail.com or lyra_jr@hotmail.com. Tel/Fax: 552107921056844.
}

cognition loss, resulting in polypharmacy.

Polypharmacy increase the susceptibility to adverse drug reactions in elderly patients and they find it difficult to understand the disease and its treatment (Vinks et al., 2009; Cranor and Christensen, 2003; Paolisso, 2010). Taken together, these circumstances often produce poor control of blood glucose levels and a high incidence of drug-related problems (DRPs) that negatively affect the quality of life (QoL) of these patients (Cranor and Christensen, 2003; Fornos et al., 2006). Growing evidence demonstrates that models of diabetes care which involve pharmacists are able to contribute to improved patient outcomes (Armor et al., 2009).

Since 1990s, pharmaceutical practice has been moving from a technical to a social paradigm, with services becoming patient-focused $(\mathrm{Li}, 2003)$. The practice of 
pharmaceutical care has been defined by Hepler and Strand (1990) as "the responsible provision of pharmacotherapy, with the goal of achieving defined therapeutic outcomes in health and the improvement of quality of life of the population. In last years, pharmaceutical care services had a logical extension called medication therapy management (MTM) that is defined as "the optimization therapeutic outcomes through improved medication use" and "reduce the risk of adverse events, including adverse drug reactions (de Oliveira et al., 2010). Although there were some studies about MTM in Brazil, this practice is unusual in community pharmacies. Thus, the aim of this study was to develop and implement a pilot community pharmacy MTM program and evaluate its impact on the clinical outcomes and the QoL of a group of elderly patients with type 2 DM.

\section{METHODS}

\section{Design and study site}

This study was a prospective trial pilot (single group) study conducted by intervention in a single community pharmacy in Aracaju, Brazil, from February to November 2009. Study approval was obtained from the Ethics Committee in Research of the University Hospital of the Federal University of Sergipe (Protocol $n^{\circ}$ 0137.0.107.000-07).

\section{Patient selection}

We recruited a convenience sample through referrals of eligible patients from the University Hospital clinic. This comprised patients of both genders aged from 60 to 75 years. Included were patients were eligible if they had a confirmed diagnosis of type $2 \mathrm{DM}$ according to the American Diabetes Association (ADA, 2005) and were taking antidiabetic medications. We excluded patients unable to attend scheduled visits, and patients who missed more than 3 consecutive visits (Al Mazroui et al., 2009; Garção and Cabrita, 2002). The target population was recruited over approximately 2 months. All patients agreeing to participate in the study signed a consent form in accordance with Resolution CNS no 196/96.

\section{The MTM program}

The MTM program comprised monthly visits scheduled over 10 months; each lasted 40-60 min. The 9 steps of good practice of MTM were followed: (1) establishment of a pharmacist-patient therapeutic relationship; (2) collection, analysis, and interpretation of relevant information; (3) identification and classification of DRPs; (4) establishment of drug therapy goals with the patient; (5) determination of viable drug therapy alternatives; (6) selection of the best drug therapy alternative; (7) developing a plan of care; (8) implementation of an individual plan and monitoring of the same; and (9) follow-up (Hepler and Strand, 1990). For the identification of DRPs, the Pharmacists' Work-Up of Drug Therapy model was used. This classifies DRPs into Necessity (DRPs 1 and 2), Effectiveness (DRPs 3 and 4), Safety (DRPs 5 and 6), and Compliance (DRPs 7) (Strand et al., 2004). At this stage of the process, the description of DRPs was based on information provided by the patients, for example, the problem or condition of the patient, the medication(s) involved, and the association of the medication(s) with the patient's problem. This identification requires clinical skills, a thorough knowledge of the patient as a person, as well as knowledge of the drug and the illness, good communication skills, and a systematic care process (Strand et al., 2004).

During the MTM program, educational interventions aimed at personal transformation were conducted and the patient's "critical awareness" was encouraged. These were inspired by the approach of participatory social orientation proposed by Freire (1983). Educational measures included oral and written instructions (with folders and slides). Patients were informed about DM and its complications; appropriate drug dosages, side effects, and medication storage. Changes in lifestyle particularly with regard to diet and physical exercise-were stressed, as was the importance of the management of the signs and symptoms of DM through selfmonitoring (Al Mazroui et al., 2009; American Diabetes Association, 1996). These educational interventions were reinforced at each encounter with the patient. Moreover, changes in pharmacotherapy were discussed with the patients and physicians when necessary. All such changes were suggested in view of the recommendations of the American Diabetes Association (ADA, 2005). It is important to highlight that pharmacists alone could not alter pharmacotherapy: patients were referred to their physician for therapy adjustment.

A detailed assessment of the pharmacotherapy was carried out after each interview, looking at the characteristics of each of the drugs in depth. This assessment was always made with regard to the characteristics and problems of each individual patient. Pharmacists assessed the safety and effectiveness of both drugs and lifestyle, coming to the conclusion of whether or not one or more DRPs had arisen or were likely to arise. Then a strategy was determined to solve the problem (Fornos et al., 2006).

\section{Data collection}

At each of the consultations, sociodemographic, clinical, and pharmacotherapeutic data were obtained. This included data on levels of capillary blood glucose, and blood pressure (BP), and measurements of Body Mass Index (BMI) and waist circumference (Sociedade Brasileira de Diabetes. Diretrizes da Sociedade Brasileira de Diabetes, 2007; Lipschitz, 1994; World Health Organization, 1998). Therefore, glycosylated hemoglobin (HbA1c) was obtained to patients at baseline (first interview) and at the end of the study (10-months). QoL evaluation was performed using a generic instrument-the Medical Outcomes Studies 36-item Short Form (SF-36®; Portuguese version) Ciconelli et al., (1999). This is was administered twice at the start and end of the 10-month period of the program (Freire $P$ 1983). This instrument has 8 domains, which assess functional capacity, physical aspects, pain, general state of health, vitality, social, emotional, and mental health aspects. Each domain was measured on a scale of 0 to 100 , with scores closer to 100 representing a better QoL. In this study, the concept of QoL was defined like a multidimensional construct, which comprises physical, mental, and social aspects as well as the perception of the general wellbeing of the individual (Hepler and Strand, 1990).

\section{Statistical analysis}

Data collected were double entered and then analyzed using the BioEstat ${ }^{\circledR}$ database (Version 5.0, National Council for Scientific and Technological Development [CNPq], Brazil). Statistical analyses were conducted: these included frequency, mean, and standard deviation (SD).

Student's paired $t$ test was used for continuous normally distributed variables in clinical and humanistic outcomes between baseline and end of study and $p<0.05$ was used to indicate a significant difference. The Cohen's $d$ test was applied for 


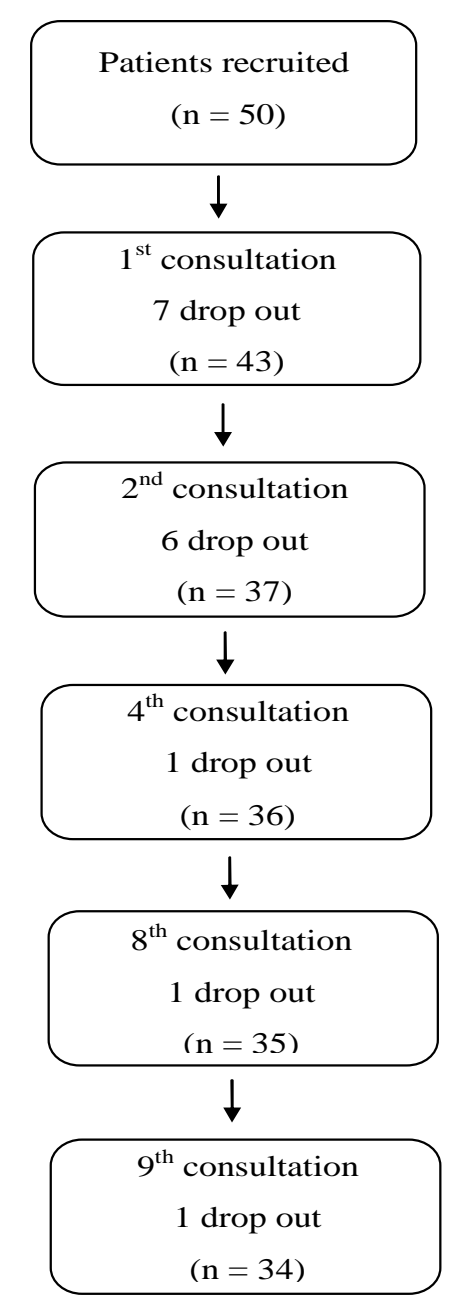

Figure 1. Patient abandonment during a community pharmacy study in Aracaju, Brazil, February to November 2009.

measuring significant effect size for all variables of QoL.

\section{RESULTS}

In total, 50 patients were invited to participate in the MTM program pilot, and of these, 34 completed the study (drop out rate $=32 \%$ ). The reasons reported for dropping out were: lack of interest $(50 \% ; n=8)$, loss of contact $(18.75 \% ; n=3)$, moving to another city $(12.5 \%$; $=2$ ), limited mobility ( $12.5 \% ; n=2)$, and hospitalization $(6.25 \% ; n=1)$ (Figure 1).

The mean patient age was 66 years, and approximately half were female and had not finished high school. The median of DM diagnosis time was 12 years. Most of elderly $(76.5 \%, \mathrm{n}=26)$ were retired and had access to the public $(44.1 \%, \mathrm{n}=15)$ and private $(41.9 \%, \mathrm{n}=14)$ health care service. Their medications mainly were
Table 1. Sociodemographic characteristics of elderly patients $(n=34)$ attending at a community pharmacy in Aracaju, Brazil from February to November 2009.

\begin{tabular}{cc}
\hline Age (years) & \\
\hline Gender & $65.9(4.7)^{*}$ \\
\hline Female & $\%(\mathbf{n})$ \\
Male & $52.9(18)$ \\
& $47.1(16)$
\end{tabular}

$\begin{array}{lc}\text { Marital status } & \\ \text { Married } & 73.5(25) \\ \text { Single } & 11.7(4) \\ \text { Divorced } & 8.8(3) \\ \text { Widow } & 5.9(2)\end{array}$

Level of education
$\begin{array}{lc}\text { Literate } & 5.9(2) \\ \text { Elementary school } & 50.0(17) \\ \text { High School } & 23.5(8) \\ \text { College } & 20.6(7)\end{array}$

$\begin{array}{lc}\text { Profession } & \\ \text { Retired } & 76.5(26) \\ \text { Homemaker } & 11.8(\mathrm{n}=4) \\ \text { Employment relationship } & 5.9(\mathrm{n}=2) \\ \text { Others } & 5.9(2)\end{array}$

Access to health service

Public

Private

Both

$\begin{array}{cc}\text { Diagnostic Time } & 13.5(9.9)^{\star} \\ \text { Up to } 10 \text { years } & 35.3(n=12) \\ 10 \text { to } 20 \text { years } & 35.3(n=12) \\ >20 \text { years } & 29.4(n=10)\end{array}$

\section{Risk Factors for Diabetes}

Hypertension $^{\mathrm{a}}$

$79.4(\mathrm{n}=27)$

Family history

$70.9(n=24)$

Increased waist circumference

$58.8(n=20)$

Dyslipidemia

$47.0(n=16)$

Sedentarism

$47.0(n=16)$

Neuropathy

$8.8(\mathrm{n}=3)$

Nephropathy

$2.9(n=1)$

Retinopathy

$2.9(n=1)$

Tobacco smoking

$2.9(\mathrm{n}=1)$

* Mean (standard deviation (SD) ; ${ }^{a}$ BP greater than $140 / 90 \mathrm{mmHg}$

acquired in Farmácia Popular do Brasil for low cost. Regarding risk factors, a majority had family history of DM, hypertension and, central obesity (Table 1). 
Table 2. Drug-related problems (DRPs) identified $(n=117)$ and resolved in elderly patients at a community pharmacy in Aracaju Brazil, according to the Pharmacist Workup Drug Therapy classification (February to November 2009).

\begin{tabular}{|c|c|c|c|c|}
\hline \multirow{2}{*}{ Necessities related to the medications } & \multirow{2}{*}{$\begin{array}{c}\text { Type of } \\
\text { DRP }\end{array}$} & \multirow{2}{*}{$\begin{array}{c}\text { DRP Real } \\
\text { Identified (Resolved) }\end{array}$} & \multirow{2}{*}{$\begin{array}{c}\text { DRP Potential } \\
\text { Identified (Resolved) }\end{array}$} & \multirow{2}{*}{ Total n (\%) } \\
\hline & & & & \\
\hline \multirow{2}{*}{ Indication } & 1 & $6(5)$ & $5(4)$ & \multirow{2}{*}{$25(21.4)$} \\
\hline & 2 & $13(10)$ & $1(1)$ & \\
\hline \multirow{2}{*}{ Effectiveness } & 3 & $10(8)$ & $0(0)$ & \multirow{2}{*}{$40(34.2)$} \\
\hline & 4 & $25(24)$ & $5(3)$ & \\
\hline \multirow{2}{*}{ Safety } & 5 & $9(8)$ & $5(5)$ & \multirow{2}{*}{$22(18.8)$} \\
\hline & 6 & $6(6)$ & $2(2)$ & \\
\hline Compliance & 7 & $25(20)$ & $5(5)$ & $30(25.6)$ \\
\hline Total & & $94(81)$ & $23(20)$ & 117 \\
\hline
\end{tabular}

Table 3. Clinical parameters in the baseline and final evaluation of elderly patients $(n=34)$ at a community pharmacy in Aracaju Brazil, February to November 2009.

\begin{tabular}{lccc}
\hline Clinical parameter & $\begin{array}{c}\text { Baseline } \\
\text { mean (SD) }\end{array}$ & $\begin{array}{c}\text { Final } \\
\text { mean (SD) }\end{array}$ & $\mathbf{p}^{*}$ \\
\hline Glycosylated hemoglobin (\%) & $8.9(2.1)$ & $6.9(0.9)$ & $<0.001^{*}$ \\
Capillary glucose $(\mathrm{mg} / \mathrm{dL})$ & $230.9(103.3)$ & $176.4(76.5)$ & $0.005^{*}$ \\
Systolic BP (mmHg) & $148.5(19.7)$ & $128.9(14.7)$ & $<0.001^{*}$ \\
Diastolic BP (mmHg) & $83.1(12.1)$ & $76.1(9.8)$ & $<0.001^{*}$ \\
BMI (kg.m ${ }^{-2}$ ) & $27.9(3.8)$ & $28.1(4.0)$ & 0.089 \\
Waist measurement (cm) & & & \\
Men & & & $0.003^{*}$ \\
Women & $98.3(10.8)$ & $96.6(10.4)$ & $0.036^{*}$ \\
\hline
\end{tabular}

${ }^{*}$ Statistical significance: $\mathrm{p}<0.05 ; \mathrm{BP}=$ blood pressure; $\mathrm{BMI}=$ body mass index.

In this study, the median of medication used was 6 , and 28 patients $(82 \%)$ used 5 or more medications, resulting in polypharmacy. The most widely used medications were for the cardiovascular system $(41.9 \%, \mathrm{n}=89)$, specifically inhibitors of the renin-angiotensin system $(10.8 \%, \mathrm{n}=23)$ and medications which regulate the alimentary tract and metabolism $(33.9 \%, \mathrm{n}=72)$. Medication mainly used in the treatment of DM comprised $32 \%(n=68)$. The most commonly used oral antidiabetics were metformin, and glibenclamide.

In total, 117 DRPs were identified, with a mean of 3.4 (1.9) DRPs per patient. The largest DRP category was Effectiveness (Table 2). Of the total DRPs detected, 94 $(80 \%)$ were actual and $23(20 \%)$ potential. During patient follow-ups, 101 DRPs (86.3\%) were resolved, with 81 actual and 20 potential DRPs.

A total of 500 drug therapy interventions were performed and documented. These included advice to the doctor to cease medications causing adverse reactions (23\%), adjusting medication intervals (15\%), explanation of the importance of improving adherence to treatment, $(11 \%)$, request to the doctor to increase the dose to improve the effectiveness of pharmacotherapy $(10 \%)$ and information to seniors on managing selfmedication $(6 \%)$. Furthermore, $48.5 \%$ of the resolved DRPs required decisions from physicians. Thus, a cooperative working relationship between the research pharmacist, doctors and patients were key to solving and preventing DRPs in pharmacy. As a result, physicians accepted all recommendation for changes to the medication regimen.

In addition, 360 educational interventions were documented by the pharmacist. The most frequent were: advice on changes in lifestyle (14\%), explanations about the importance of storage of medicines (12\%), counseling on the disease $(10 \%)$ and clarification of concerns about administration of medications (dose, time, duration of treatment and route of administration) (10\%).

At the end of the MTM program the patients' mean $\mathrm{HbA} 1 \mathrm{c}$ decreased $2.0 \%$, a significant difference between the baseline and final evaluation (Table 3 ). Of these $73.5 \%(\mathrm{n}=25)$ patients achieved the target HbA1c 
Table 4. SF36® Quality of life domain scores at baseline and final evaluation for 34 elderly patients at a community pharmacy in Aracaju, Brazil from February to November 2009.

\begin{tabular}{lccc}
\hline Domain & $\begin{array}{c}\text { Baseline } \\
\text { mean (SD) }\end{array}$ & $\begin{array}{c}\text { Final evaluation mean } \\
\text { (SD) }\end{array}$ & $\mathbf{p}^{*} \mathbf{h}$ \\
\hline Functional capacity & $68.8(26.2)$ & $74.5(23.8)$ & $0.022^{*}$ \\
Physical aspects & $61.7(42.3)$ & $78.7(38.5)$ & $0.003^{*}$ \\
Pain & $57.3(26.3)$ & $71.3(32.1)$ & $0.003^{*}$ \\
General state of health & $66.6(17.2)$ & $71.3(20.1)$ & $0.026^{*}$ \\
Vitality & $65.0(16.6)$ & $76.9(19.9)$ & $<0.001^{*}$ \\
Social aspects & $82.7(26.0)$ & $86.7(22.4)$ & 0.235 \\
Emotional aspects & $67.6(42.2)$ & $78.4(39.2)$ & 0.127 \\
Mental health & $66.8(21.6)$ & $78.6(18.2)$ & $<0.001^{*}$ \\
\hline
\end{tabular}

*Statistical significance: $p<0.05$.

of $<7 \%$ (Wubben and Vivian, 2008). There were also significant improvements in mean capillary blood glucose measurements, BP (systolic and diastolic), and waist circumference, before and after the MTM program. It is noteworthy that $56 \%(n=19)$ of the patients achieved capillary blood glucose control $(<200 \mathrm{mg} / \mathrm{dL}), 62 \%(\mathrm{n}=$ 21) exhibited BP improvement, and $26.5 \%(n=9)$ achieved waist circumference control (for men $<102 \mathrm{~cm}$ and for women $<88 \mathrm{~cm}$ ) (Ferreira et al.2006; Funnell and Brown 2008) For BMI, a baseline of $53 \%(n=18)$ of the elderly were classified as overweight and $47 \%(n=16)$ as eutrophic, with no statistically significant difference $(p<$ 0.05 ) at the end of the study. Changes in clinical parameters are shown in Table 3.

The SF-36® scores for each domain are shown in Table 4. A significant difference was observed between the baseline and final evaluation in the domains of functional capacity, physical aspects, pain, general state of health, vitality, and mental health. For the domains of social and emotional aspects, mean scores increased but the difference was not statistically significant. Regarding the magnitude of the effect size showed an intermediate effect for domains of vitality $(d=0.6494 ; r=0.3088)$ and mental health $(d=0.5908 ; r=0.2833)$.

\section{DISCUSSION}

In Brazil, few Pharmaceutical care studies evaluated the improvements in clinical and humanistic outcomes. These studies usually were carried out with a small number of patients ( $n=30-64)$, on blood pressure control and in communities, pharmacies and ambulatories (Castro and Correr, 2007; Lyra et al., 2007). Then, DM MTM pilot program successfully implemented, representing an innovative approach in health care services delivered in community pharmacy in Brazil and may to be extended more broadly.

The socio-demographic characteristics, type of access to health services, levels of polypharmacy, and risk factors presented by the elderly in this program suggest that the study sample was typical of an elderly population of type 2 diabetes patients (Wermeille et al., 2004; Cranor and Christensen, 2003; Al Mazroui et al., 2009; Castro and Correr, 2007; Cranor et al., 2003; Clifford et al., 2005). In this study, the proportion of patients who experienced some form of DRPs is similar to the findings of Rao et al. (2007) but is higher than values reported in other studies (Doucette et al., 2005; Paulino et al., 2004). One reason for this high rate in our study may have been the presence of a pharmacist qualified to identify and resolve DRPs (Rao et al., 2007). In this study, the mean DRP value per patient was close to the values found by Fornos et al. (2006) and Roozendaal and Krass (2009). These results demonstrate the high prevalence of DRPs in elderly patients with type $2 \mathrm{DM}$, and this emphasizes the need for pharmacotherapeutic follow-up of these patients (Zhou et al., 2009).

Finally, the category of DRPs most commonly found in this study - effectiveness - corroborates data found by Fornos et al. (2006) but differs from most previous studies (Wermeille et al., 2004; Roozendaal and Krass, 2009; Zhou et al., 2009). This discrepancy may be partially explained by the lack of standardization in DRP classification. Although the elderly patients had a mean of 14 years of type 2 DM diagnosis, they still used mainly hypoglycemic first choice for the treatment of DM, such as metformin and glibenclamide (Sociedade Brasileira de Diabetes. Diretrizes da Sociedade Brasileira de Diabetes, 2007). Probably, the clinical inertia has been one of the factors that influenced in a greater frequency of DRPs effectiveness.

The positive impact of pharmaceutical interventions on the values of most of the clinical variables was an important result of this study. For $\mathrm{HbA} 1 \mathrm{c}$, the reduction of $2.0 \%$ was higher than that seen in other recent research and the same is true for reductions in BP and capillary blood glucose seen in this study (Wermeille et al., 2004; Fornos et al., 2006; Al Mazroui et al., 2009; Clifford et al., 2005). 
Furthermore, the large proportion of patients who achieved the clinical goals for DM shows that pharmaceutical interventions can provide clinically relevant differences for these patients (American Diabetes Association, 2005). According to the UK Prospective Diabetes Study (1998), a reduction of at least $0.5 \%$ in $\mathrm{HbA} 1 \mathrm{c}$ levels leads to an estimated $18.5 \%$ reduction in microvascular complications and a $10.5 \%$ lowering of DM-related mortality. Regarding BP, the difference of $10 / 5 \mathrm{mmHg}$ seen in the present study would lead to a reduction of $44 \%$ in the risk of stroke, a $37 \%$ lowering of the risk of microvascular complications, and a $32 \%$ reduction in DM-related mortality (UK Prospective Diabetes Study Group, 1998).

In the present study, BMI was the only clinical variable which showed no significant difference before and after intervention. This may be because lack of power this pilot study and compared to younger patients, the elderly are less likely or less capable of performing physical activities that minimize weight gain (Abbatecola et al., 2008). It is also worth highlighting other healthcare professionals such as doctors, nutritionists, and physical trainers are needed to support lifestyle change in elderly patients (Ahrens et al., 2003; Guimarães and Ciolac, 2004).

Although there was reduction in the clinical parameter of waist circumference, measurements did not reach the cutoff recommended by the World Health Organization (WHO, 1998). However, while waist circumference is one of the most widely used indicators for measuring the centralized distribution of adipose tissue in individual and collective assessments (WHO, 1995) differences in body composition between different age and racial groups hinder the development of universal cutoff points (Ferreira et al., 2006).

In this study, the inclusion of educational interventions was considered fundamental to the success of the MTM program. As part of this approach, it was important for the elderly to assume an active role in their educational development. Similar findings were reported in a recent systematic review of 4 studies; the review showed a significant improvement in pharmacotherapeutic outcomes amongst elderly patients who used an individualized education provided by a pharmacist (George et al., 2008). According to the National Standards for Diabetes Self-Management Education (2008) (Funnell and Brown, 2008) there are basic guiding principles for the development of these interventions, and this resource also discusses the need for continued support to sustain the progress made by participants of educational programs, stating that education about DM is effective in improving both patients' clinical outcomes and QoL.

In this study, improvements in patient QoL scores were probably the result of the effectiveness of educational interventions, and of greater patient contact with their clinical pharmacists. The results from the SF-36 analysis are similar to those found by Elnour et al. (2008) and Al
Mazrouiu et al. (2009). These data also support the use of this generic QoL instrument for the evaluation of the impact of education programs for DM patients (Brown et al., 2000). For the social aspects and emotional aspects domains, improvement was observed, but the differences were not statistically significant. In the case of social aspects it was noted that there were high baseline scores, reflecting a possible ceiling effect in this domain. Polypharmacy, a characteristic of the sample studied, may have contributed to the lack of positive impact on the emotional aspects domain scores (Lyra et al., 2007). The results of effect size (Cohen's d) and the improvement of the physical aspect, pain, vitality and mental state of patients suggest that the changes associated with the program have put to practical significance. Despite the results show the improvement in functional capacity and general health status of patients, we could not prove the influence of the program due to the small magnitude of size effect.

\section{Limitations}

In this study, the dropout rate was relatively high. However, the reported reasons for this were consistent with other studies (Garção and Cabrita, 2002; Lee et al., 2006). According to Martinez-Perez (2004) the abandonment of monitoring programs reflects poor patient knowledge about their illness. In this study, elderly patients' lack of experience in receiving care from pharmacists could have been the main reason for their drop out of the service. MTM program abandonment rates and their causes are important indicators and need to be taken into account when developing appropriate strategies for the design of the studies in this area.

In this pilot, 10 months was considered an adequate evaluation period. However, since pilot studies like this one cannot be used for more than hypothesis generation, new long-term studies are now necessary to validate the clinical and humanistic benefits demonstrated in this study. The limitations of a pilot program (1 research site and the small sample size) should be considered when developing future studies; more patients and pharmacies are needed. Moreover, the inclusion of a control group and the evaluation of the economic impact of this service should be included in future research to increase the robustness and reliability of the results.

Regarding QoL assessment, although the SF-36 has been frequently used in MTM research, several studies have criticized the lack of specificity and sensitivity of this instrument for this function (Billups et al., 2000; Malone et al., 2001; Kheir et al., 2004). Thus the develop-ment of an instrument designed to specifically measure the impact on QoL as a result of MTM services could optimize the detection and evaluation of positive results from this program (Schultz, 2001; Pickard and Hung, 
2006).

\section{Conclusion}

This pilot study at a community pharmacy in Brazil demonstrated that MTM interventions coupled with an educational program led to improvements QoL scores and clinical parameters for a group of elderly patients. From the results obtained it could be suggested that community pharmacists may play a valuable role in health care provide to patients with type 2 diabetes by focusing on optimizing the benefits of pharmacotherapy. Future studies are needed for to enhance the methodology used, including the following: evaluation of MTM structure and process; construction, validation and standardization of research tools; correct randomization; description of the sample size; impact of educational interventions; and evaluation of economic results.

\section{REFERENCES}

Abbatecola AM, Maggi S, Paolisso G (2008). New approaches to treating type 2 Diabetes Mellitus in the elderly: Role of incretin therapies. Drugs Aging 25(11):913-925

Ahrens RA, Hower M, Best AM (2003). Effects of weight reduction interventions by community pharmacists. J. Am. Pharm. Assoc. 43(5) 583-590.

Al Mazroui NR, Kamal MM, Ghabash NM, Yacout TA, Kole PL, McElnay JC (2009). Influence of pharmaceutical care on health outcomes in patients with Type 2 diabetes mellitus. Br. J. Clin Pharmacol. 67(5): 547-557.

American Diabetes Association (ADA) (1996). Self-monitoring of blood glucose [consensus Statement]. Diabetes Care 19:S62-66

American Diabetes Association (ADA) (2005). Standards of medical care in diabetes [consensus Statement]. Diabetes Care 28:S4-36.

Armor BL, Britton ML, Dennis VC, Letassy NA (2009). A review of pharmacist contributions to diabetes care in the United States. J. Pharm. Pract. 23(3):250-264.

Assunção MCF, Santos IS, Costa JSD (2002). Clinical management of diabetic patients: process evaluation in Pelotas, Southern Brazil. Rep Public Health 18:205-211.

Billups SJ, Malone DC, Carter BL (2000). Relationship between drug therapy noncompliance and patient characteristics, health-related quality of life, and health care costs. Pharmacotherapy 20:941-949

Brown GC, Brown MM, Sharma S (2000). Quality of life associated with diabetes mellitus. p. 42

Castro MS, Correr CJ (2007). Pharmaceutical care in community pharmacies: Practice and research in Brazil. Ann. Pharmacother. 41: 1486-1493.

Chatterjee A, Harris SB, Leiter LA, Fitchett DH, Teoh H, Bhattacharyya OK (2012). Managing cardiometabolic risk in primary care: Summary of the 2011 consensus statement. Can. Family Physician 58(4):389393.

Ciconelli RM, Ferraz MB, Santos WS, Meinão I, Quaresma MR (1999). Brazilian-Portuguese version of the SF-36. A reliable and valid quality of life outcome measure. Rev. Bras. Reumatol. 39(3):143-150.

Clifford RM, Davis WA, Batty KT, Avis TM (2005). Effect of a pharmaceutical care program on vascular risk factors in type 2 diabetes. Diabetes Care 28:771

Cranor CW, Bunting BA, Christensen DB (2003). The Asheville Project: longterm clinical and economic outcomes of a community pharmacy diabetes care program. J. Am. Pharm. Assoc. 43: 173-184.

Cranor CW, Christensen DB (2003). The Asheville Project: Short-term outcomes of a community pharmacy diabetes care program. J. Am. Pharm. Assoc. 43:149-159. de Oliveira DR, Brummel AR, Miller DB (2010). Medication Therapy Management: 10 Years of Experience in a Large Integrated Health Care System. J. Manage. Care Pharm. 16(3): 185-95.

Doucette WR, McDonough RP, Klepser D, McCarthy R (2005). Comprehensive medication therapy management: identifying and resolving drug-related issues in a community pharmacy. Clin. Ther. 27(7):1104-1111.

Elnour AA, El Mugammar IT, Jaber T, Revel TMD, James CM (2008). Pharmaceutical care of patients with gestational diabetes Mellitus. J. Eval. Clin.Pract. 14:131-140.

Ferreira MG, Valente JG, Gonçalves-Silva RMV, Sichieri R (2006). Accuracy of waist circumference and waist-to-hip ratio as predictors of dyslipidemia in a cross-sectional study among blood donors in Cuiabá Mato Grosso State, Brazil. Reports Public Health 22(2):307-314

Fornos JA, Floro AN, Carlos AJ, Mercedes GM, Beatriz E (2006). A pharmacotherapy follow-up program in patients with type-2 diabetes in community pharmacies in Spain. Pharm World Sci. 28:65-72.

Freire P (1983). Education for critical consciousness. NewYork (NY): Continuum Press.

Funnell MM, Brown TL (2008). Childs BP National Standards for Diabetes Self-Management Education. Diabetes Care; 31(Suppl 1):597- S104.

Garção JA, Cabrita J (2002). Evaluation of pharmaceutical care program for hypertensive patients in rural Portugal. J. Am. Assoc. 42: 858-64.

George J, Elliott RA, Stewart DC (2008). A systematic review of interventions to improve medication taking in elderly patients prescribed multiple medications. Drugs Aging. 25 (4):307-324

Guimarães GV, Ciolac EG (2004). Metabolic syndrome: physical educator approach Rev. Soc. Cardiol. Estado de São Paulo 14(4):659-670.

Hepler CD, Strand LM (1990). Opportunities and responsibilities in pharmaceutical care. Am. J. Hosp. Pharm. 47:533-543.

Kheir NM, Van Mil F, Shaw JP, Sheridan JL (2004). Health-related quality of life measurement in pharmaceutical care: targeting an outcome that matters. Pharm World Sci. 26(3):125-128.

Lee JK, Grace KA, Taylor AJ (2006). Effect of a pharmacy care program on medication adherence and persistence, blood pressure, and lowdensity lipoprotein cholesterol: a randomized controlled trial. JAMA 296(21):2563-2571.

Li SC (2003). An overview of community pharmacist interventions assessing cost-effectiveness and patients' willingness to pay. Dis Manage Health Outcomes 11(2):95-110.

Lipschitz DA (1994). Screening for nutritional status in the elderly. Primary Care, 21(1): 55-67.

Lyra Jr. DP, Kheir N, Abriata JP, Rocha CE, Santos BC, Pelá IR (2007). Impact of pharmaceutical care interventions in the identification and resolution of drug-related problems and on quality of life in a group of elderly outpatients in Ribeirão Preto (SP), Brazil. Ther. Clin. Risk Manag. 3(6):989-998.

Malone DC, Carter BL, Billups SJ, Valuck RJ, Barnette DJ, Sintek CD, Okano GJ, Ellis S, Covey D, Mason B, Jue S, Carmichael J, Guthrie K, Sloboda L, Dombrowski R, Geraets DR, Amato MG (2001). Can clinical pharmacists affect SF-36 scores in veterans at high risk for medication-related problems? Med. Care 39:113-122.

Martínez-Pèrez SR, Sànchez-Alonso FJ, Baena MI (2004). Effects of the pharmacist intervention in patients with high blood pressure without pharmacological treatment. Seguim Farmacoter 2(3):181-8.

Paolisso G (2010). Pathophysiology of diabetes in elderly people. Acta bio-medica 81:47-53.

Paulino El, Bouvy ML, Gastelurrutia MA, Guerreiro M, Buurma H (2004). Drug related problems identified by European community pharmacists in patients discharged from hospital. Pharm. World Sci. 26(6):353-360

Pickard AS, Hung SY (2006). An update on evidence of clinical pharmacy services' impact on health-related quality of life. Ann. Pharmacother 40:1623-1634.

Rao D, Gilbert A, Strand LM, Cipolle RJ (2007). Drug therapy problems found in ambulatory patient populations in Minnesota and South Australia. Pharm. World Sci. 29(6):647-654.

Roozendaal VBW, Krass I (2009). Development of an evidence-based checklist for the detection of drug related problems in type 2 diabetes. 
Pharm. World Sci. 31(5):580-595.

Schultz M (2001). Applying health status instruments in pharmaceutical care research. Proceedings of the 2nd International Working Conference on Quality Issues in Pharmaceutical Care Research. Hillerod, Denmark.

Sociedade Brasileira de Diabetes (2007). Diretrizes da Sociedade Brasileira de Diabetes: Tratamento e acompanhamento do Diabetes Mellitus. São Paulo: Sociedade Brasileira de Diabetes.

Strand LM, Cipolle RJ, Morley PC, Frakes MJ (2004). The impact of pharmaceutical care pratice on the practitioner and the patient in the ambulatory practice setting: twenty- five years of experience. Curr. Pharm. Des. 10:3987-4001.

UK Prospective Diabetes Study Group (UKPDS). (1998). Intensive blood glucose control with sulphonylureas or insulin compared with conventional treatment and risk of complications in patients with type 2 diabetes (UKPDS 33). Lancet 352:837-853.

Vinks THAM, Egberts TCG, Lange TM, De Koning FHP (2009). Pharmacist-Based medication review reduces potential drug-related problems in the elderly: The SMOG controlled trial. Drugs Aging 26(2):123-133.
Wermeille J, Bennie M, Brown I, McKnight J (2004). Pharmaceutical care model for patients with type 2 diabetes: integration of the community pharmacist into the diabetes team - a pilot study. Pharm. World Sci. 26:18-25.

World Health Organization (WHO) (1995). Physical status: the use and interpretation of anthropometry [WHO Technical Report Series 854] Geneva: World Health Organization.

World Health Organization (WHO). (1998).Obesity: preventing and managing the global epidemic [WHO Technical Report Series 894]. Geneva: World Health Organization.

Wubben DP, Vivian EM (2008). Effects of Pharmacist Outpatient Interventions on Adults with Diabetes Mellitus: A Systematic Review. Pharmacotherapy 28(4):421-36.

Zhou X, Ji L, Luo Y, Han X, Zhang X, Sun X, Ren Q, Qiao Q (2009). Risk factors associated with the presence of diabetes in Chinese communities in Beijing. Diabetes Res. Clin. Pract. 86:233-238. 